\title{
Removal of tar base from coal tar aromatics employing solid acid adsorbents
}

\author{
Jeffrey Chi-Sheng $\mathrm{Wu}^{\mathrm{a}, *}$, Hsueh-Chang Sung ${ }^{\mathrm{a}}$, Yu-Fu Lin ${ }^{\mathrm{a}}$, Shi-Long Lin ${ }^{\mathrm{b}}$ \\ a Department of Chemical Engineering, National Taiwan University, Taipei, Taiwan 10617, ROC \\ ${ }^{\mathrm{b}}$ New Material Research and Development Department, China Steel Corporation, Kaohsiung 81233, Taiwan, ROC
}

Received 17 November 1999; received in revised form 30 March 2000; accepted 17 July 2000

\begin{abstract}
Aromatic compounds from coal tar generally contain a small amount of tar bases, such as quinoline and isoquinoline. These nitrogen-containing compounds can poison the acid-type catalysts and downgrade the aromatic products because of stinking odor. Four solid acid catalysts, silica-alumina, $\mathrm{HY}, \mathrm{NH}_{4}$-mordenite, and $\gamma$-alumina are used to remove tar bases by adsorption. Wash oil (WO), refined naphthalene (RN), and an intermediate distillate from the China Steel coke plant (Taiwan) contain quinoline ranged from 0.03 to $8.9 \%$. Quinoline and isoquinoline can be selectively removed from a mixture due to their strong chemisorption on acidic sites, thus the remaining compounds are not disturbed following adsorption. Naphthalene, a neutral compound, is physically adsorbed on solid acids, and is desorbed near its boiling point. Silica-alumina gives the best adsorption results because its wide-ranging pore sizes are accessible to the bulky quinoline molecule. The adsorption of $\mathrm{HY}$ and mordenite are significantly decreased because of the extremely diffusion limitation of quinoline in pore channels. Solid acids can be completely regenerated in air at $500-600^{\circ} \mathrm{C}$. The adsorption ability of silica-alumina can be completely restored even after three cycles of regeneration. The adsorption rate increases with temperature although the capacity decreases. This work demonstrates that the adsorption through the use of solid acids is an effective method that can be used to reduce the amount of tar bases in coal tar aromatics. (c) 2000 Elsevier Science B.V. All rights reserved.
\end{abstract}

Keywords: Quinoline; Coal tar; Adsorption; Silica-alumina; HY zeolite; Mordenite

\section{Introduction}

Coal is converted into a variety of solid, liquid, and gaseous products when thermally pyrolyzed or distilled by heating without contact with air.

\footnotetext{
* Corresponding author. Tel.: + 886-2-3631944; fax: + 886$2-3623040$.

E-mail address: cswu@ccms.ntu.edu.tw (J.C.-S. Wu).
}

Liquid or coal tar contains many chemicals, mostly benzene, toluene, xylene, naphthalene, and methylnaphthalene [2]. These chemicals are used as raw materials for producing many fine chemicals used in medicines, dyes, and pigments. Coal tar aromatics may still contain undesirable tar bases, even after purification from distillation or crystallization. Tar bases are compounds of nitrogen-containing aromatics. Quinoline is one of the 
major compounds in the tar base family. The odor of quinoline can make coal tar products unacceptable to customers. Furthermore, the oxidation of contaminated quinoline in aromatics during storage can downgrade the products. Acidtype catalysts were found to be poisoned if reactant containing quinoline or other tar bases $[4,6,11]$. Removal of quinoline can be difficult because its molecular structure is similar to naphthalene. A commercial product from the coke plant of China Steel Chemical Co., refined naphthalene (RN), contains several hundred ppm of quinoline even following two-stages of recrystallization.

Industrial recovery or removal of tar-bases from wash oil (WO) is traditionally carried out by extraction, using mineral acids such as sulfuric acid. The extracted tar-bases in an aqueous solution are then neutralized and recovered from the mixture using liquid-liquid separation. Kawasaki Steel Co. developed a novel process that could recover indole from coal tar using oligomerization technique [10]. However, if the production of coal tar aromatics was on a small scale, using such a process would not be economical because of the substantial equipment investment required. Even if the tar bases are removed only by acid washing without recovery equipment, the direct discharge of used acidic sludge can upset wastewater treatment plant because of high BOD and low $\mathrm{pH}$.

Audeh (1979) [1] reported that nitrogen compounds of Arab light oil can be effectively removed by contacting with $\mathrm{HCl}$ adsorbed silica-alumina and $\mathrm{X}$ zeolite. The regeneration of adsorbent was considerably complicated using $\mathrm{NH}_{3}$ to remove $\mathrm{Cl}$ followed by heat treatment under Ar. The basic asphaltenes could be selectively removed from asphaltene-containing hydrocarbon feed through the adsorption using transition-metal-oxide acids catalysts. Regeneration was carried out by steaming and calcination in air $[7,9,12]$. Nitrogen compounds were removed from a hydrotreated shale oil by adsorption on US-Y zeolites [5]. Sakanishi et al. (1995) [13] reported that quinoline was adsorbed on supported alumina sulfate and was recovered using supercritical $\mathrm{CO}_{2}$ from methylnaphthalene oil.
Solid acids such as silica-alumina and zeolites are well known for their acidic properties. Acidity is due to unbalanced charges within their oxide structure. These acids comprise Brönsted and Lewis acid sites, which are used as cracking catalysts in the petroleum industry. Both acidic sites offer a high affinity for basic compounds, like pyridine and quinoline [5] Oxide solid acid is oil resistant and thermally stable making it suitable for processing coal tar aromatics. This study focuses on the adsorption of tar bases using solid acids to remove undesired quinoline and isoquinoline from coal tar aromatics produced by the China Steel coke plant.

\section{Experimental}

The following four solid acid catalysts were chosen for adsorption, amorphous silica-alumina (Strem chemicals), $\gamma$-alumina (Strem chemicals), HY zeolite (PQ zeolites B.V., CBV 740), and $\mathrm{NH}_{4}$-mordenite (PQ zeolites B.V., LZ-M8). The $\mathrm{SiO}_{2} / \mathrm{Al}_{2} \mathrm{O}_{3}$ ratios of silica-alumina, $\mathrm{HY}$ zeolite, and $\mathrm{NH}_{4}$-mordenite provided by manufacturer are $7.25,42$, and 10 , respectively. The specific surface area of silica-alumina, $\gamma$-alumina, HY zeolite, and $\mathrm{NH}_{4}$-mordenite were measured by $\mathrm{N}_{2}$ adsorption. These solid acids were thermally activated at $400-600^{\circ} \mathrm{C}$ in air to remove water and hydrocarbon impurity, and then were stored in a desiccant for later use. Three coal tar aromatics, $\mathrm{WO}, \mathrm{RN}$, and an intermediate distillate (MNO) were obtained from the coke plant of China Steel Chemical Co., Taiwan. WO is an aromatic mixture with boiling points ranging from $200-300^{\circ} \mathrm{C}$. $\mathrm{RN}$ is a commercial product of white crystalline that is purified through the use of two-stage crystallization. MNO is one of the streams taken from the middle of the distillations. These coal tar aromatics were used directly without any further treatment.

Equilibrium (saturated) adsorption was performed in a covered glass beaker to prevent the evaporation of hydrocarbons. The glass beaker typically contained $1-5 \mathrm{~g}$ of solid acid with coal tar aromatics. The adsorption of coal tar aromatics was performed at temperatures between $25-$ 
$100^{\circ} \mathrm{C}$. The adsorption of $\mathrm{RN}$ was at $90^{\circ} \mathrm{C}$, that is, slightly higher than its melting points. The weight ratio of coal tar aromatics to solid acid ranged from 1 to 20. Equilibrium was attained by checking the composition of aromatics when it did not change. Normally it took $24 \mathrm{~h}$ to attain equilibrium. Steady flow adsorption was carried out in a packed-bed column. Approximately $50 \mathrm{~g}$ of solid acids were charged in the column, which had an inside diameter of 1.5 and length of $10 \mathrm{~cm}$. The solid acid is extruded pellet with 2-mm diameter and $4-5 \mathrm{~mm}$ in length. The residency time was calculated from the flow rates and the packed-bed volume. The column was maintained at adsorption temperature by heating tape. The desorption of used solid acids was performed in a quartz tube inside an oven as illustrated in Fig. 1. The desorbed components were carried by $\mathrm{N}_{2}$ and were collected in an acetone-filled bottle. Solid acid, under $\mathrm{N}_{2}$ flow, was heated from room temperature to $200^{\circ} \mathrm{C}$ within $\sim 10 \mathrm{~min}$ and stayed at that temperature for $1 \mathrm{~h}$, then acetone was sucked from bottle and fresh acetone was refilled. The same procedure was repeated from 200 to 600 with $100^{\circ} \mathrm{C}$ step. Therefore, the desorbed components in acetone can be analyzed by gas chromatography (GC) at each temperature. Air regeneration of used solid acids was in a furnace at 500 and $600^{\circ} \mathrm{C}$. Solid acids turned black or brown after adsorption. The regeneration was completed when the solid acid reverted to its original white color because the original adsorption capacity was restored. All coal tar aromatics were dissolved and diluted in acetone before GC analysis. A GC equipped with mass spectroscope was used to identify the components initially and another GC equipped with FID was used to measure the concentration of components. An HP-5 capillary column was used to analyze WO and MNO. The analysis of RN used a CP-Wax 52CB capillary column.

The weight loss of adsorbed solid acids in thermal desorption was performed employing thermogravimetric analysis (TGA). The strength of solid acids was characterized using various indicators in benzene solvent. The quantity of acid sites was titrated by base, which contained $0.1 \mathrm{~N} \mathrm{n}$ butylamine dissolved in benzene. The color change of the indicators normally took several hours to 2 days during titration.

\section{Results and discussion}

The amount of acidity of the three solid acids is listed in Table 1. The acidic strength is indicated

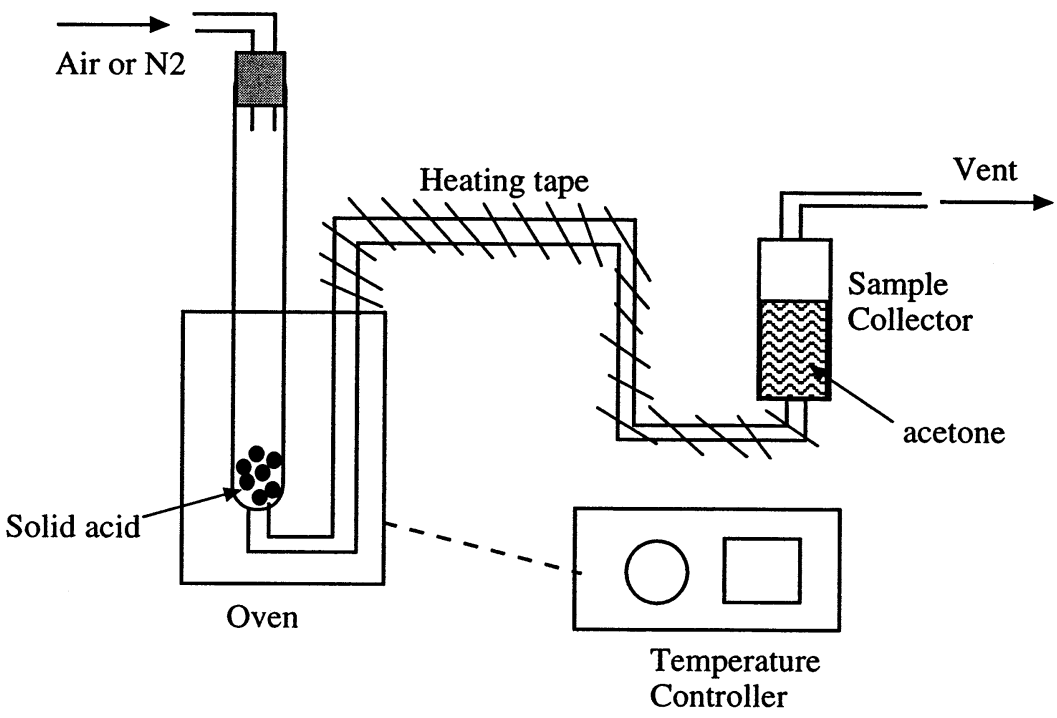

Fig. 1. Schematic of solid acid regeneration unit. 
Table 1

The specific area and acidity of solid acids ${ }^{\mathrm{a}}$

\begin{tabular}{lllll}
\hline & $\mathrm{SiO}_{2}-\mathrm{Al}_{2} \mathrm{O}_{3}$ & $\mathrm{HY}$ & $\mathrm{NH}_{4}$-mordenite & $\gamma$-Alumina \\
\hline Specific area $\left(\mathrm{m}^{2} / \mathrm{g}\right)$ & 425 & 750 & 480 & 200 \\
$H_{0}=-3.3(\mathrm{mmole} / \mathrm{g})$ & 1.189 & 0.605 & 0.628 & - \\
$H_{0}=-5.6$ & 0.421 & 0.533 & - & - \\
$H_{0}=-8.2$ & - & - & - & - \\
\hline
\end{tabular}

a Titrated by n-butylamine in benzene solvent, indicators, dicinnamalacetone $H_{0},-3.3$; Benzalacetophenone $H_{0}$, -5.6 ; anthraquinone $H_{0},-8.2$.

by Hammett acidity function $H_{0}$, which was measured when the indicator changed color. The amount of acidity is given by the amount of n-butylamine titrated. For silica-alumina, the amount of acidity stronger than $H_{0}=-3.3$ is $1.189 \mathrm{mmole} / \mathrm{g}$, and that stronger than $H_{0}=-$ 5.6 is $0.421 \mathrm{mmole} / \mathrm{g}$. The low acidity of mordenite could be caused by incomplete decomposition of $\mathrm{NH}_{4}$-form under our heat treatment condition. The acidity of $\gamma$-alumina was nearly undetected during measurement. The original compositions of WO, RN and MNO are listed in Table 2. They represent the coal tar aromatics with various compositions. Quinoline is a weak heterocyclic base with basic ionization constant $K a=8.9 \times 10^{-10}$ [8]. Quinoline and isoquinoline are the major base components in these samples, which ranged from $\sim 0.003(\mathrm{RN})$ to $8.9 \%$ (MNO).

Table 3 lists the equilibrium adsorption results of WO mixed with various solid acids at room temperature for $24 \mathrm{~h}$. Quinoline and isoquinoline are effectively reduced in WO. The remaining components stay at about the same level, indicating that quinoline and isoquinoline are selectively removed by solid acids. Silica-alumina leads the highest adsorption performance. The concentrations of quinoline and isoquinoline are reduced from 2.64 to 1.21 and 0.87 to $0.29 \%$, respectively. The quinoline reduction on $\gamma$-alumina is the lowest one because it contains the least acidity. Generally the uptakes of quinoline and isoquinoline follow the order of the amount of acidity (Table 1). The uptake of quinoline is not only related to the amount of acidity, but also the acidic strength of solid acids. It would expect that HY zeolite should have better adsorption capability because it has the higher acidic strength and largest spe- cific area (Table 1). However, the internal acidic site is not accessible for quinoline because it is extremely diffusion-limited caused by the penetration of channels in Y zeolite [3]. Fig. 2 presents the WO adsorptions on silica-alumina, HY and mordenite. The concentrations of quinoline and isoquinoline gradually decline on silica-alumina and reach a constant value after $24 \mathrm{~h}$. The concentrations of quinoline and isoquinoline on $\mathrm{HY}$ and mordenite quickly decline to low levels within $1 \mathrm{~h}$ and only a small amount more quinoline and isoquinoline can be removed within $20 \mathrm{~h}$. Obviously, quinoline and isoquinoline adsorptions only occur on the outer shell of crystals of HY and mordenite, thus they are saturated in a short period of time. Most acidic sites of silica-alumina are available for quinoline/isoquinoline because silica-alumina contains a wide-range of pore

Table 2

Compositions of coal tar aromatics

\begin{tabular}{lccc}
\hline wt. \% & WO & RN & MNO \\
\hline Naphthalene & 3.64 & 99.32 & 28.81 \\
Quinoline & 2.64 & 0.025 & 8.92 \\
Isoquinoline & 0.87 & 0.005 & 1.81 \\
$\alpha$-Methyl-naphthalene & 7.80 & 0.006 & 11.30 \\
$\beta$-Methyl-naphthalene & 14.71 & 0.034 & 33.19 \\
Biphenyl & 7.61 & - & - \\
Acenaphthene & 18.07 & - & - \\
Dibenzofuran & 14.11 & - & - \\
Flourene & 7.26 & - & - \\
Thianaphthene & - & 0.574 & - \\
Dimethyl-naphthalene & - & - & 6.94 \\
Indole & - & 0.028 & - \\
Others $^{\text {a }}$ & 23.29 & 0.008 & 9.03 \\
\hline
\end{tabular}

a Others include anthracene, phenanthrene, $\mathrm{H}_{2} \mathrm{O}$, etc. Samples provided by China Steel Corp., Taiwan. 
Table 3

The reduction of bases of WO by solid acids ${ }^{\mathrm{a}}$

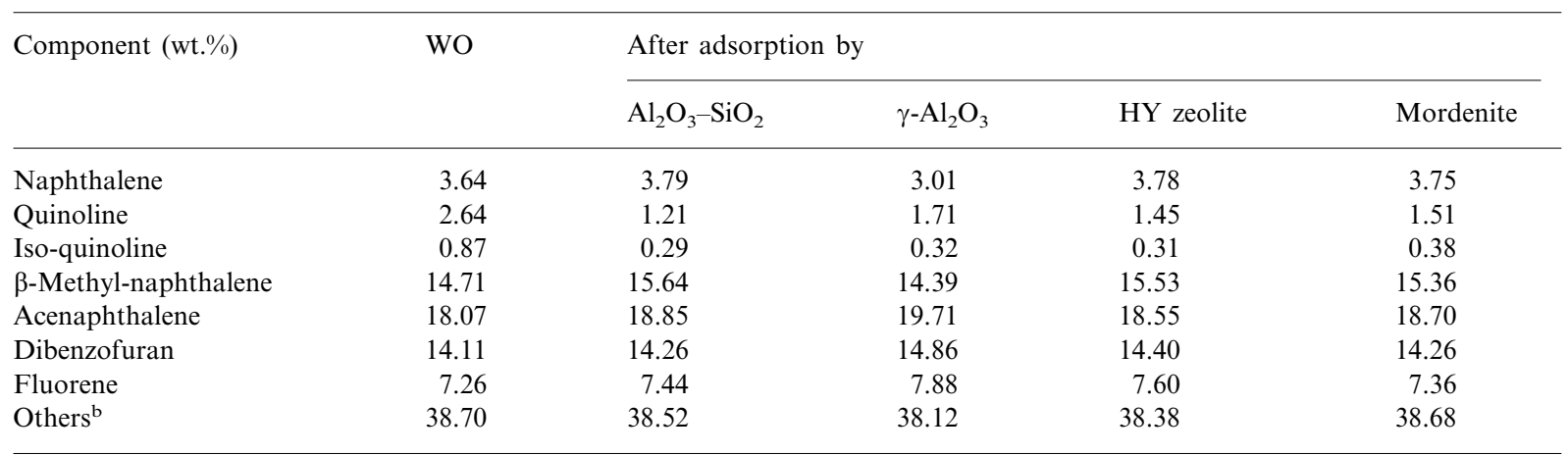

\footnotetext{
${ }^{\text {a }}$ Solid acids pre-calcined at $400^{\circ} \mathrm{C}, 4 \mathrm{ml} \mathrm{WO}+2 \mathrm{~g}$ solid acid, adsorption $24 \mathrm{~h}$ at room temperature.

${ }^{\mathrm{b}}$ Others include $\alpha$-methyl-naphthalene, biphenyl, thianaphthene, dimethyl-naphthalene, indole, anthracene, phenanthrene, $\mathrm{H}_{2} \mathrm{O}$, etc.
}

sizes. It also takes longer to reach adsorption equilibrium. The opening aperture of mordenite is even smaller than that of Y-zeolite, thus its adsorption capacity of quinoline/isoquinoline is even lower than that of HY. Air regeneration also indicated that $\mathrm{HY}$ and mordenite required a higher temperature and a much longer time than silica-alumina. The limited diffusion is the major hurdle using HY and mordenite. Therefore, adsorption experiments focused on silica-alumina.

Table 4 displays the concentration changes of quinoline and isoquinoline on $\mathrm{RN}$ in the 15 and $60 \mathrm{~min}$ of adsorption at $90^{\circ} \mathrm{C}$, using silica-alumina. Except quinoline and isoquinoline, the rest of the compounds are almost unchanged after adsorption. The adsorption was performed at the weight ratio of $\mathrm{RN}$ to silica-alumina of 5 . The solid acid is not saturated because the original concentration of quinoline and isoquinoline are extremely low in RN. Isoquinoline can be completely removed in $15 \mathrm{~min}$, but it takes $60 \mathrm{~min}$ to completely remove quinoline. This is attributed to that isoquinoline adsorption is stronger (see later discussion) and, thus, takes less time. Furthermore, the concentration of isoquinoline is lower than that of quinoline.

The equilibrium adsorption capacity of silicaalumina was given by isotherms displayed in Fig. 3 at the temperature ranged from 25 to $90^{\circ} \mathrm{C}$. The isotherms were derived by varying the weight ratio of $\mathrm{MNO} /$ silica-alumina. The amount of adsorbed quinoline and isoquinoline on silicaalumina was calculated from the difference of initial and final concentrations of MNO in adsorption. The adsorption capacity of silica-alumina depends on temperature and quinoline/isoquinoline concentration. The higher temperature gives a lower adsorption capacity. The uptake increases with an increasing concentration at a low temperature. However, at $90^{\circ} \mathrm{C}$, the uptake increases only slightly with increasing concentration. Possibly the adsorption at higher

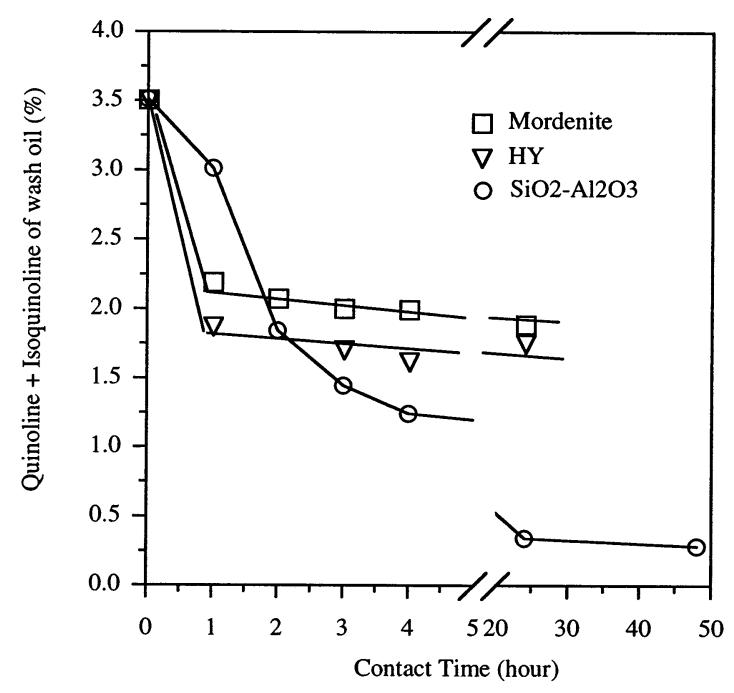

Fig. 2. The concentration changes of WO adsorption on solid acids. 
Table 4

The removal of tar bases in $\mathrm{RN}(5 \mathrm{~g} \mathrm{RN}+1 \mathrm{~g} \text { silica-alumina })^{\mathrm{a}}$

\begin{tabular}{|c|c|c|c|}
\hline $\begin{array}{l}\text { Component } \\
\text { (wt. \%) }\end{array}$ & $\mathrm{RN}$ & $\begin{array}{l}\text { Adsorbed at } \\
15 \mathrm{~min}\end{array}$ & $\begin{array}{l}\text { Adsorded at } 60 \\
\text { min }\end{array}$ \\
\hline Naphthalene & 99.32 & 99.26 & 99.28 \\
\hline Thianaphthene & 0.574 & 0.597 & 0.582 \\
\hline Quinoline & 0.025 & 0.005 & 0.000 \\
\hline Iso-quinoline & 0.005 & 0.000 & 0.000 \\
\hline $\begin{array}{l}\text { a-Methyl-naphth } \\
\text { alene }\end{array}$ & 0.006 & 0.004 & 0.005 \\
\hline $\begin{array}{l}\text { b-Methyl-napht } \\
\text { halene }\end{array}$ & 0.034 & 0.041 & 0.032 \\
\hline Indole & 0.028 & 0.030 & 0.023 \\
\hline Others $^{\mathrm{b}}$ & 0.008 & 0.063 & 0.078 \\
\hline
\end{tabular}

a Silica-alumina pre-calcined at $500^{\circ} \mathrm{C}$.

${ }^{\mathrm{b}}$ Others include dimethyl-naphthalene, phenol, etc.

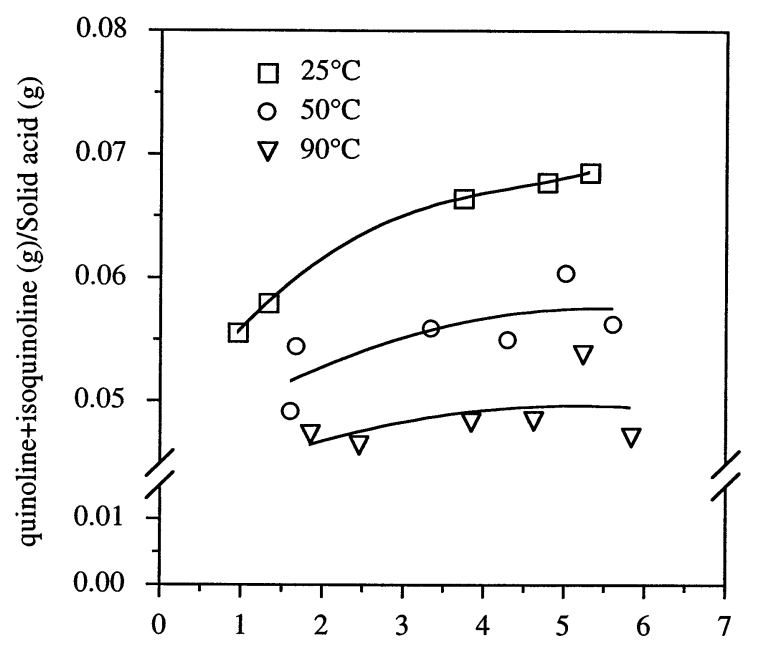

Concentration of quinoline + isoquinoline of $\mathrm{MNO}(\%)$

Fig. 3. Adsorption isotherms of $\mathrm{SiO}_{2}-\mathrm{Al}_{2} \mathrm{O}_{3}$ with $\mathrm{MNO}$.

temperature requires stronger acidic sites (i.e. stronger chemisorption), thus uptake is imposed by the quantity of stronger acidic sites available. These isotherms can be used to estimate the minimum amount of silica-alumina required to remove quinoline/isoquinoline for a given concentration. Beside the equilibrium adsorption capacity of solid acids, the rate of adsorption is also crucial for practical application. The adsorption rate relates to adsorption temperature. Fig. 4 illustrates the temperature effect of quinoline ad- sorption of WO on silica-alumina. The temperature varies from room temperature to $100^{\circ} \mathrm{C}$. The adsorption of quinoline can be observed from the decline curve of concentration within the first $2 \mathrm{~h}$. The rate of adsorption increases with increasing temperature. Low temperature is favorable for higher uptake, however, low temperature decreases the adsorption rate. For practical applications, there will be an optimum temperature for obtaining an economical adsorption capacity while removing quinoline at a reasonable rate.

The TGA result of $\mathrm{RN}$ adsorbed silica-alumina is displayed in Fig. 5. The weight of $\mathrm{RN}$ adsorbed silica-alumina is significantly decreased near $200^{\circ} \mathrm{C}$, then it is almost unchanged while the temperature rises and reaches $700^{\circ} \mathrm{C}$. The desorbed components at 200 and $600^{\circ} \mathrm{C}$ are listed in Table 5. Naphthalene is attributed to the $40 \%$ weight loss of RN adsorbed silica-alumina. Most of the naphthalene is desorbed near its boiling point, $218^{\circ} \mathrm{C}$. This finding implies that the adsorption of naphthalene is merely a physical adsorption on solid acid because naphthalene is a neutral compound. Naphthalene is loosely stuck in the pores and surface of silica-alumina during adsorption. The substantial amount of desorbed naphthalene contains no quinoline and isoquinoline. Therefore, adsorbed naphthalene on silica-

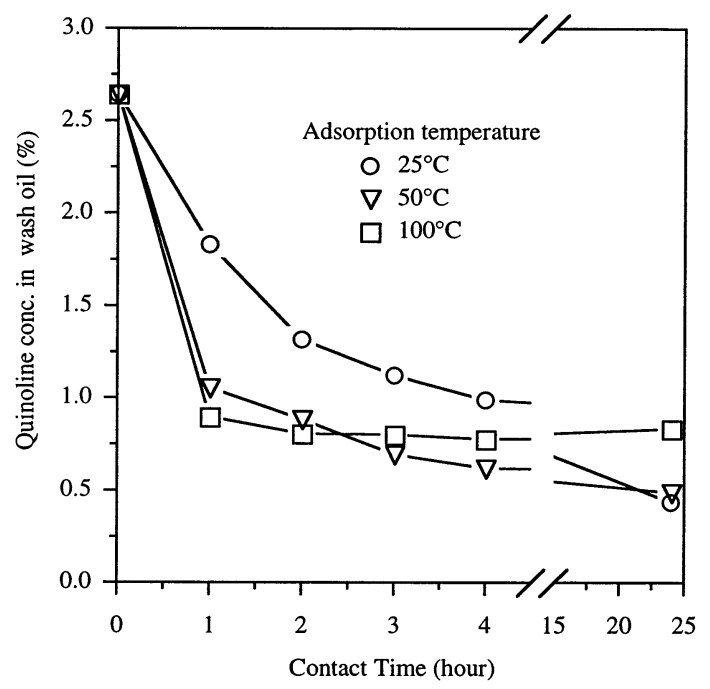

Fig. 4. The effect of adsorption temperatures of WO on $\mathrm{SiO}_{2}-\mathrm{Al}_{2} \mathrm{O}_{3}$. 


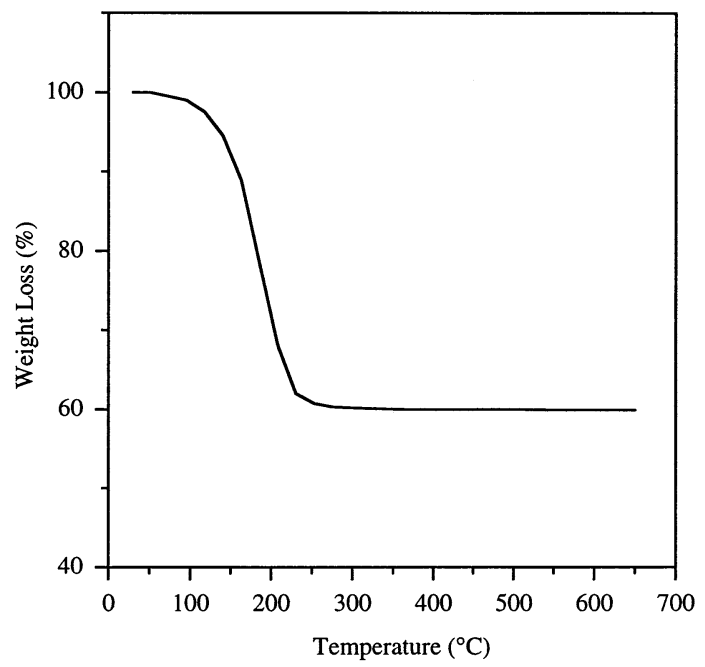

Fig. 5. TGA of $\mathrm{RN}$ adsorbed $\mathrm{SiO}_{2}-\mathrm{Al}_{2} \mathrm{O}_{3}$ under $\mathrm{N}_{2}$ environment.

Table 5

The components of desorption in $\mathrm{RN}$ adsorbed silicaalumina $^{\mathrm{a}}$ under $\mathrm{N}_{2}$ flow

\begin{tabular}{|c|c|c|c|}
\hline \multirow[t]{2}{*}{$\begin{array}{l}\text { Components } \\
\text { (wt.\%) }\end{array}$} & \multirow[t]{2}{*}{$\mathrm{RN}$} & \multicolumn{2}{|c|}{$\begin{array}{l}\mathrm{SiO}_{2}-\mathrm{Al}_{2} \mathrm{O}_{3} \text { desorption } \\
\text { component at }\end{array}$} \\
\hline & & $200^{\circ} \mathrm{C}$ & $600^{\circ} \mathrm{C}$ \\
\hline Naphthalene & 99.32 & 99.37 & 99.12 \\
\hline Quinoline & 0.0249 & 0 & 0.1282 \\
\hline Isoquinoline & 0.0048 & 0 & 0.0331 \\
\hline $\begin{array}{l}\alpha \text {-Methyl-naphthalen } \\
\mathrm{e}\end{array}$ & 0.006 & 0.0035 & 0.0051 \\
\hline $\begin{array}{l}\beta \text {-Methyl-naphthalen } \\
\mathrm{e}\end{array}$ & 0.034 & 0.0328 & 0.0373 \\
\hline Thianaphthene & 0.574 & 0.565 & 0.556 \\
\hline Indole & 0.0277 & 0 & 0.0368 \\
\hline Others & 0.0084 & 0.0287 & 0.0083 \\
\hline
\end{tabular}

${ }^{a} \mathrm{RN}$ adsorbed silica-alumina was obtained the adsorption of $5 \mathrm{~g}$ RN, $1 \mathrm{~g}$ silica-alumina.

alumina should be recovered near $200^{\circ} \mathrm{C}$ before air regeneration to prevent excess loss of $\mathrm{RN}$. The major component of $600^{\circ} \mathrm{C}$ desorption is still naphthalene because it is the major component of RN. The amount of desorption is very small at $600^{\circ} \mathrm{C}$ (Fig. 5). Quinoline and isoquinoline are not desorbed at 200 until $600^{\circ} \mathrm{C}$. The original and desorbed concentrations of quinoline and isoquinoline change from 0.0249 to
0.1282 and 0.0048 to $0.0311 \%$, respectively. Both increments are about five times, which coincide with the $\mathrm{RN} /$ solid acid ratio (Table 5). That is, quinoline and isoquinoline will not be desorbed until near $600^{\circ} \mathrm{C}$. The concentrations of quinoline and isoquinoline are extremely low thus they will be adsorbed on the most available, that is the strongest, acidic sites. Therefore, under this circumstance, strong chemisorption occurs. This is the reason why silica-alumina can selectively remove quinoline and isoquinoline from a coal tar mixture even at a very low concentration. Indole does not appear at $200^{\circ} \mathrm{C}$. It is desorbed at $600^{\circ} \mathrm{C}$ and the concentration is only slightly higher than the original. Indole adsorption was found to be weaker than that of quinoline [5], and might be gradually desorbed between 200 and $600^{\circ} \mathrm{C}$.

The desorption components of $\mathrm{MNO}$ adsorbed silica-alumina are displayed in Fig. 6. Most of naphthalene was desorbed below $220^{\circ} \mathrm{C}$, which is close to its boiling point $\left(218^{\circ} \mathrm{C}\right)$. Quinoline and isoquinoline become the major desorbed components starting at $300^{\circ} \mathrm{C}$, that is still higher than their boiling points $(238$ and $242^{\circ} \mathrm{C}$, respectively). The maximum desorption of quinoline occurs at $450^{\circ} \mathrm{C}$ while the des-

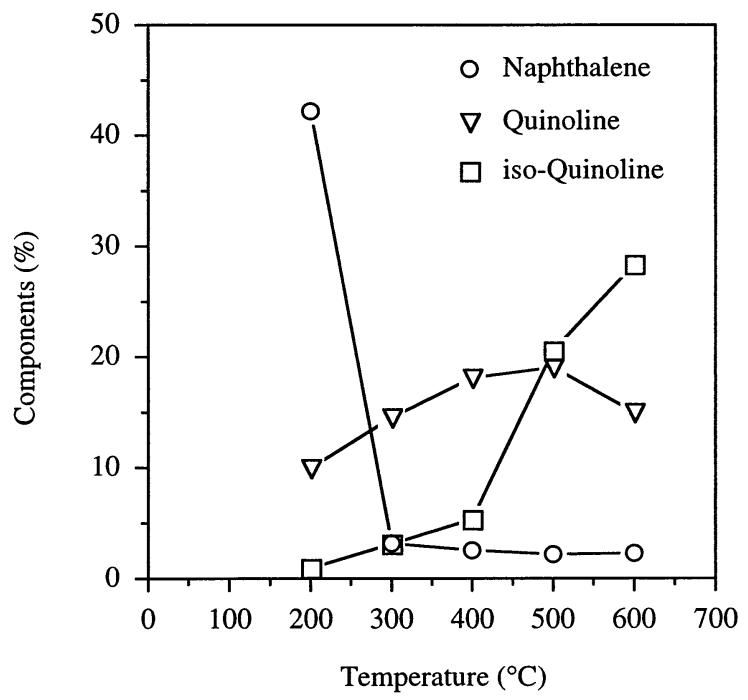

Fig. 6. The desorption component of $\mathrm{MNO}$ adsorbed $\mathrm{SiO}_{2}-$ $\mathrm{Al}_{2} \mathrm{O}_{3}$. 
Table 6

The adsorption ability after three regenrations in air at 500 and $600^{\circ} \mathrm{C}^{\mathrm{a}}$

\begin{tabular}{llcc}
\hline Temperature $\left({ }^{\circ} \mathrm{C}\right)$ & Number of regeneration & Removal quinoline $\%$ & Removal isoquinoline $(\%)$ \\
\hline $500(60 \mathrm{~min})$ & 1 & 97 & 100 \\
& 2 & 94 & 100 \\
$500(120 \mathrm{~min})$ & 3 & 100 & 100 \\
& 1 & 96 & 100 \\
$600(60 \mathrm{~min})$ & 2 & 100 & 100 \\
& 1 & 100 & 100 \\
$600(120 \mathrm{~min})$ & 2 & 98 & 100 \\
& 3 & 100 & 100 \\
& 1 & 100 & 100
\end{tabular}

\footnotetext{
${ }^{\text {a }}$ Ratio of RN/silica-alumina, 5; adsorption at $90^{\circ} \mathrm{C}$; adsorption time, $45 \mathrm{~min}$; removal percentage $=($ original concentration - concentration after adsorption)/original concentration $\times 100 \%$.
}

orption of isoquinoline is required even above $600^{\circ} \mathrm{C}$. Compared with the desorption of $\mathrm{RN}$ on silica-alumina, quinoline and isoquinoline are gradually desorbed as the temperature rises. The amounts of quinoline and isoquinoline in MNO are substantially higher than those in RN (Table 2). The adsorption of such an amount will occur on the acidic sites with wide ranges of acidic strength. Thus, the wide desorption temperature reflects the chemisorption strength between quinoline/isoquinoline and silica-alumina. The shape of molecule is also an important factor. The chemisorbed isoquinoline is stronger than chemisorbed quinoline, resulting in a higher desorption temperature [5].

Table 6 summarizes the adsorption ability of silica-alumina after three regenerations in air, at 500 and $600^{\circ} \mathrm{C}$ for 1 and $2 \mathrm{~h}$, respectively. The removal of quinoline and isoquinoline in $\mathrm{RN}$ is complete or nearly complete. The adsorption ability following three regenerations shows no difference from that of a fresh one, indicating that the acidity is completely restored. Regeneration below $400^{\circ} \mathrm{C}$ was not completed because the solid acids were still brown or black in color, even with a longer heating time. Thus, regeneration should be at least $500^{\circ} \mathrm{C}$ for $1 \mathrm{~h}$.

For industrial applications, a packed-bed is a convenient way to operate in a continuous pro- cess. Fig. 7 displays the break-through curve of the quinoline and isoquinoline removal of $\mathrm{RN}$ in the silica-alumina packed-bed column by flow-through adsorption at $90^{\circ} \mathrm{C}$. The residency time is required approximately $1 \mathrm{~h}$ (see Table 4). The effluent of RN shows no quinoline and isoquinoline until after the 140 min operation. Desorption and regeneration can be thus performed after $140 \mathrm{~min}$, depending on the maximum allowance of quinoline in $\mathrm{RN}$ product. Unlike a

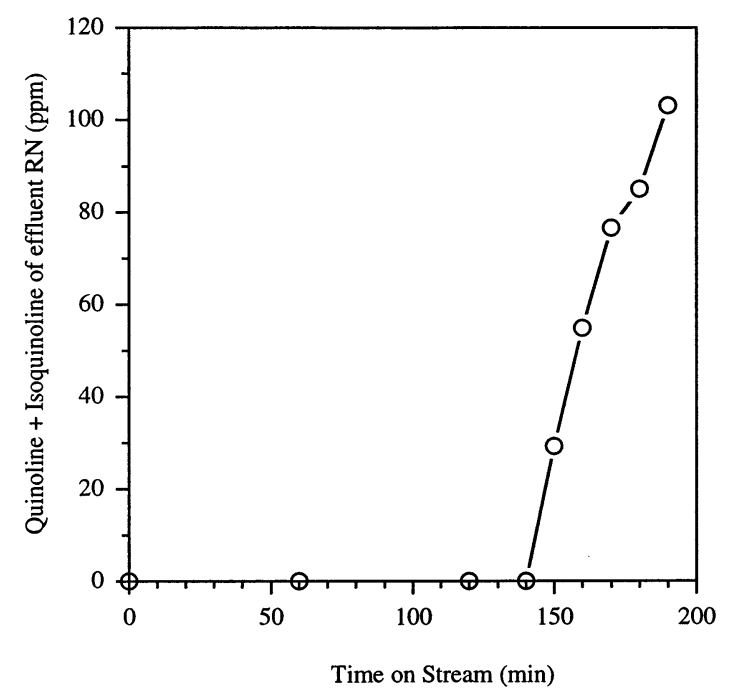

Fig. 7. The adsorption of $\mathrm{RN}$ in packed-bed column at $90^{\circ} \mathrm{C}$ (residency time, $1 \mathrm{~h}$ ). 
batch process, the capacity of silica-alumina is not yet saturated for adsorbing quinoline of such amounts found in RN. The maximum capacity of silica-alumina cannot be not fully utilized if a continuous process with a limited residency time is required.

\section{Conclusion}

This study presents a feasible and effective method for removing tar bases such as quinoline from coal tar aromatics. Strong chemisorption of quinoline and isoquinoline occurs so that solid acids can selectively remove undesirable quinoline without disturbing the major compounds of WO, $\mathrm{RN}$, and MNO. Silica-alumina shows the best adsorption results among four solid acids. The pore-diffusion limitation of HY and mordenite markedly downgrades their capacity for removing quinoline and isoquinoline. The regeneration can be achieved by simply burning off the adsorbed compounds. Solid acid catalysts are commonly and widely available from catalyst suppliers. The removal of tar base using solid acids is a simple and economical process needing no major capital investment.

\section{Acknowledgements}

The authors would like to thank the China Steel Corporation for financially supporting this research under the project number RE87605.

\section{References}

[1] C.A. Audeh, US Patent 4,137,154 (1979).

[2] G.T. Austin, Chreve's Chemical Progress Industries, fifth ed., MaGraw-Hill, New York, 1984.

[3] A. Corma, V. Fornés, F. Rey, Quinoline as probe molecule for determination of external brönsted and lewis acidity in zeolites, Zeolites 13 (1993) 56-59.

[4] A. Corma, V. Fornés, J.B. Montón, A.V. Orchillés, Cataltyic cracking of alkanes on large pore, high $\mathrm{SiO}_{2} /$ $\mathrm{Al}_{2} \mathrm{O}_{3}$ zeolites in the presence of basic nitrogen compounds. Influence of catalyst structure and composition in the activity and selectivity, Ind. Eng. Chem. Res. 26 (1987) 882-886.

[5] J. Ellis, J. Korth, Removal of nitrogen compounds from hydrotreated shale oil by adsorption on zeolite, J. Fuel 73 (10) (1994) 1569-1573.

[6] C.M. Fu, A.M. Schaffer, Effect of nitrogen compounds on cracking catalysts, Ind. Eng. Chem. Prod. Res. Dev. 24 (1985) 68-75.

[7] K.A. Gould, D.C. Grenoble, L.L. Murrell, W.J.M. Pieters, US Patent 4,422,926 (1983).

[8] S.N. Holter, Kirk-Othmer Encyclopedia of Chemical Technology, vol. 19, third ed., Wiley, New York, 1982, pp. $532-533$.

[9] R.B. Long, F.A. Caruso, US Patent 4,419,219 (1983).

[10] A. Matsuura, S. Tanaka, T. Horita, N. Sato, Y. Nagaoka, O. Nishimura, A Novel Process for Tar-Base and Indole Separation from Coal Tar, Kawasaki Technical Report No. 23, October 1990, pp. 61-64.

[11] G.A. Mills, E.R. Boedeker, A.G. Oblad, Chemical characterization of catalyst. I. Poisoning of cracking catalysts by nitrogen compounds and potassium ion, J. Am. Chem. Soc. 72 (1950) 1554.

[12] Murrell L.L., Grenoble D.C., Long R.B., US Patent 4,424,114 (1984).

[13] K. Sakanishi, H. Obata, I. Mochida, T. Sakaki, Removal and recovery of quinoline bases from methylnaphthalene oil in a semicontinuous supercritical $\mathrm{CO}_{2}$ separation apparatus with a fixed bed of supoorted aluminum, Ind. Eng. Chem. Res. 34 (1995) 4118-4121. 